\title{
Do South African universities provide the required training platforms for otolaryngology specialist training?
}

\author{
Shazia Peer, Johannes Fagan
}

Background. Concern exists about the quality of specialist training platforms at South African universities and teaching hospitals.

Method. We conducted an audit of the quality of training at South African otolaryngology (ENT) training institutions from the perspective of the registrars.

Results. Some institutions were deficient in terms of supervision, theatre time, access to teaching aids and research tools, and range of surgery, and do not provide the required training platforms for
ENT specialist training. Five out of 8 institutions have produced $\leq 2$ publications in peer-reviewed journals over the past 5 years.

Conclusions. The HPCSA fails to adequately police the quality of training in South Africa. Training programme shortcomings must urgently be addressed to ensure proper education and training of otolaryngologists.

S Afr Med J 2012;102(8):691-692. DOI:10.7196/SAMJ.5545
Concerns have been voiced about a decline in the quality of specialist training at South African universities. Reasons include lack of supervision and teaching, inadequate surgical experience owing to reductions in operating lists, inadequate surgical instrumentation, and allegations that specialists do not fulfil their teaching and clinical responsibilities because of competing private practice interests.

Further concerns have been that the Health Professions Council of South Africa (HPCSA) inadequately polices the quality of specialist training programmes; that it permits training to continue at institutions that do not provide adequate platforms for specialist training; and that universities and teaching hospitals have not ensured adequate teaching facilities.

Through the College of Otorhinolaryngology of the Colleges of Medicine of South Africa (CMSA), heads of all ENT departments in South Africa agreed on the minimum staffing and infrastructural requirements for ENT training programmes. ${ }^{1}$ Their purpose was to secure adequate training platforms, empower heads of departments (HODs) when negotiating with state hospitals and universities, and provide guidelines for the HPCSA to inspect training centres.

In future, registrars will have to complete research dissertations to apply for specialist registration with the HPCSA, which raises the question whether training institutions have the research and publishing ethic to support this new requirement for specialist registration.

\section{Objectives and methods}

We aimed to gauge whether South African training institutions (i) meet minimum staffing and infrastructure requirements; (ii) provide adequate specialist supervision of registrars; and (iii) can support the HPCSA research dissertation requirement.

This was a descriptive audit conducted through the National Registrars' Committee of the South African Society of Otorhinolaryngology, Head and Neck Surgery. A questionnaire sent to ENT registrars at each South African training institution was returned to the registrars' committee chairperson (primary

Division of Otolaryngology, University of Cape Town Shazia Peer, MB BCh, FCORL (SA)

Johannes Fagan, MB ChB, FCS (SA), MMed (Otol) investigator). Registrars had no obligation to complete the questionnaire. To protect identities, the respondents and institutions are anonymous.

The questionnaire included questions relating to the minimum staffing and infrastructural requirements for ENT training programmes in accordance with the CMSA document Guidelines for the HPCSA: Minimum requirements for Otorhinolaryngology specialist training programme of 2009. ${ }^{1}$

Research output was defined as the number of publications in peer-reviewed journals per institution over the past 5 years, and was obtained from the database maintained by the academic subcommittee of the South African Society of Otorhinolaryngology, Head and Neck Surgery.

As only one registrar per institution participated, there is a risk of bias. However, most questions pertaining to provision of services, infrastructure, teaching aids, etc. were objective, with 'Yes' or 'No' responses, and hence less likely to be biased.

\section{Results}

Seven of the eight training institutions responded. One institution has not had an active full-time head of department for several years despite concerns directed to its medical school dean by the South African Society of Otorhinolaryngology, Head and Neck Surgery; at 2 institutions, respondents judged full-time HODs not to be clinically active. All institutions had more than 2 full-time specialists; yet at 2 institutions they were often unavailable to assist registrars. Only 3 out of 7 institutions met the CMSA guidelines of a full-time specialist:registrar ratio of 1:2.

Registrars should attend at least 2 theatre lists ( 4.5 hours each) per week to gain adequate surgical experience. At 3 out of 7 institutions, registrars attended $<2$ lists per week.

At 3 institutions, $25-33 \%$ of operating lists were not directly supervised. At 1 institution, the unsupervised lists were for tonsillectomies and grommets, while at the other 2 it was for general ENT lists. The number of consultant-led ward rounds varied considerably, occurring $0.5,1,3,5$ and 7 times per week. Specialist on-call assistance to registrars was not available 24 hours a day, 7 days a week, at 3 out of 7 institutions.

The CMSA document lists surgical procedures that registrars should be exposed to during their training. At 3 out of 7 institutions, registrars were exposed to only $71 \%$ of these. Endoscopic sinus surgery is central to modern ENT practice, yet registrars at 2 out of 7 institutions had no such exposure during their training. One institution did not teach rigid oesophagoscopy. 
The CMSA lists the minimum theatre equipment required for registrar training. Four institutions had only 50\%, 56\%, 67\% and 78\% of this equipment, as well as poor access to a functioning mastoid drill for mastoidectomies; no ossicular prostheses for middle ear reconstructive surgery; and no microlaryngoscopy sets for vocal cord surgery. Four institutions had $>80 \%$ of the required outpatient department equipment; however, the remaining 3 institutions had only $50 \%, 60 \%$, and $70 \%$ of this equipment. At 3 out of 7 institutions, a $0^{\circ}$ rigid nasendoscope was never/sporadically available; one frequently had no headlights available, and registrars had to provide their own.

ENT requires functioning support services such as availability of and reporting on specialised radiology, speech therapy, audiology, neurosurgery, plastic surgery, and pathology. All 7 institutions had good access to functioning support services; 6 of the 7 scored $100 \%$, and the other scored $>80 \%$.

Educational facilities including a medical library with online fulltext access to major ENT journals, free internet access, temporal bone laboratory to learn mastoid surgery with 2 bones to drill per annum, and weekly academic meetings are important for registrar training. Four institutions fulfilled these requirements. Of the remaining 3, 2 had $<50 \%$ of the required facilities. The poorest had only $29 \%$ - for not providing free internet access; not having a library with online full-text access to major ENT journals; not having a functioning temporal bone laboratory; and not having regular (weekly) divisional/ departmental academic meetings.

Despite MMed research dissertations now being an HPCSA requirement for specialist registration, registrars at only 4 institutions had protected research time. Research output, defined as the number of publications per institution in peer-reviewed journals in the past 5 years, was $66,10,9,2,2,0,0$ and 0 , respectively.

At 3 out of 7 institutions, registrars were not obliged to attend endoscopic sinus surgery and temporal bones dissection courses. There was limited/no funding available for registrars to attend courses and conferences at 4 out of 7 institutions.

\section{Discussion}

This study demonstrates that all South African universities do not provide the required training platforms for ENT specialist training. We believe that the same is true for other specialties. Major deficiencies in ENT training programmes urgently require correction to ensure that otolaryngologists are properly educated and trained. The responsibility for poor training platforms is shared by universities, hospitals and the HPCSA.

A specialist-led ward round only once a fortnight or once a week, and for a consultant on call not to be available for advice, is unacceptable for teaching and clinical service. Hospitals and universities should better monitor the activities of specialist staff, regulate private practice activities and act when staff members do not fulfil their contractual clinical and teaching responsibilities.
Registrars at some institutions receive inadequate surgical exposure and are not trained in key areas of surgery such as endoscopic sinus surgery. This hiatus must be urgently corrected to avoid exposing the public to inadequately trained specialists. Universities must ensure that registrar numbers are commensurate with the number of operating lists required to be properly trained. Outpatients and theatres must be adequately equipped, and additional training be provided to specialists responsible for training registrars where they lack certain skills.

Some universities do not meet their teaching responsibilities regarding internet access to journals, academic meetings, and specialist supervision. Universities and hospitals must ensure protected research time for registrars to complete research dissertations required for specialist registration. However, the zero/ low publication counts of some universities questions the HPCSA ambition of requiring a dissertation for specialist registration, unless dissertations that are not of a publishable standard are accepted.

\section{The way forward}

As an examining body, the CMSA has no control over the quality of training, other than using logbooks as a gatekeeper for access to the final examinations. Some universities and teaching hospitals fail to maintain adequate training platforms. The HPCSA, which has the statutory power to police and compell universities and hospitals to maintain adequate training programmes, has not fulfilled its mandate to do so.

We propose the following measures to secure adequate training standards:

1. CMSA colleges should detail the minimum requirements for training platforms for the HPCSA to use on inspection visits.

2. The HPCSA should conduct more regular, critical and in-depth evaluations of training programmes.

3. Programmes that do not fulfil the minimum requirements should be placed on probation, and closed if they fail to rectify deficiencies.

4. National registrar committees should be established through national specialist societies that can monitor and speak up about training standards.

5. A system should be put in place, such as exists in Switzerland and the UK, whereby registrars score their training departments, and submit the data online to a neutral body, e.g. the HPCSA.

6. Universities and teaching hospitals should improve monitoring of specialist staff including abuse of private practice.

\section{Reference}

1. Guidelines for the HPCSA: Minimum requirements for Otorhinolaryngology specialist training programme. Formulated by the College of Otolaryngology of the Colleges of Medicine of South Africa, 2009. 